STUDI

FRANCESI

\section{Studi Francesi}

Rivista quadrimestrale fondata da Franco Simone

185 (LXII | II) | 2018

OCTAVE MIRBEAU: UNE CONSCIENCE AU TOURNANT

DU SIĖCLE - sous la direction de Ida Merello

\title{
CATALINA GIRBEA, Le Bon Sarrasin dans le roman médiéval (1100-1225)
}

\section{Walter Meliga}

\section{(2) OpenEdition}

\section{Journals}

Édition électronique

URL : http://journals.openedition.org/studifrancesi/13181

DOI : 10.4000/studifrancesi. 13181

ISSN : 2421-5856

Éditeur

Rosenberg \& Sellier

\section{Édition imprimée}

Date de publication : 1 août 2018

Pagination : 298-299

ISSN : 0039-2944

\section{Référence électronique}

Walter Meliga, " CATALINA GIRBEA, Le Bon Sarrasin dans le roman médiéval (1700-1225)», Studi Francesi [En ligne], 185 (LXII | II) | 2018, mis en ligne le 01 septembre 2018, consulté le 06 janvier 2021. URL : http:// journals.openedition.org/studifrancesi/13181; DOI : https://doi.org/10.4000/studifrancesi.13181

Ce document a été généré automatiquement le 6 janvier 2021.

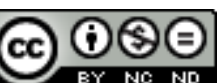

Studi Francesi è distribuita con Licenza Creative Commons Attribuzione - Non commerciale - Non opere derivate 4.0 Internazionale. 


\title{
CATALINA GIRBEA, Le Bon Sarrasin dans le roman médiéval (1100-1225)
}

\author{
Walter Meliga
}

\section{RÉFÉRENCE}

CATALINA GIRBEA, Le Bon Sarrasin dans le roman médiéval (1100-1225), Paris, Classiques

Garnier, 2014, «Bibliothèque d'histoire médiévale»10, pp. 671.

1 Il tema del «buon saracino» nel romanzo medievale è affrontato dall'autrice in questo imponente e stimolante saggio sulla base di una larga platea di fonti letterarie, principalmente francesi, e di fonti secondarie, dove troviamo anche testi antichi, scritti religiosi e cronachistici latini, romanzi, germanici e arabi, nonché di numerosi contributi critici, tutti raccolti in una bibliografia finale (pp. 593-649) di ampiezza ragguardevole. (Lascia invece a desiderare l'indice dei nomi, pp. 651-666, che, per un lavoro di quest'estensione, si sarebbe voluto distinto fra nomi letterari e no e anche analitico). Il tema è largamente presente nella narrativa del Medioevo e suscita di per sé delle domande all'interno di una società e di una cultura cristiane e in una letteratura destinata a un pubblico di guerrieri cristiani (p. 19). Qui, in estrema sintesi, il bon Sarrazin - variamente presente nei testi, dov'è rappresentato da personaggi differenti, nemico da rispettare ed eventualmente convertire e magari, quando donna, da sposare - vi incarnerebbe soprattutto un interesse per l'alterità e anche una forma premoderna di tolleranza. Le coordinate implicate dal tema sono senz'altro quelle socio-culturali nel senso più largo, comprendenti anche aspetti filosofici e religiosi e ovviamente estetici e letterari, che permettono anche una più articolata definizione delle materie romanzesche, in particolare di Grecia (antica e bizantina) rispetto a quella dominante di Bretagna, nonché una più comprensiva nozione dell'Oriente dal quale il bon Sarrazin proviene. Nel lavoro sembra tuttavia emergere una certa sopravvalutazione della forza euristica del tema e del personaggio, che, in quanto orientale e in un certo modo anche antico, sarebbe portatore di una significativa "apertura" del mondo del romanzo, soprattutto in relazione alla visione della guerra e 
della cavalleria, prima della "cristianizzazione" di quest'ultima, e, in quanto pagano, permetterebbe lo sviluppo di una poetica maggiormente incentrata sull'uomo. L'impressione è anche il prodotto di uno stile espositivo talora suggestivo ed evocativo, e che si sarebbe preferito invece maggiormente positivo e aderente ai fatti letterari e storici. 